
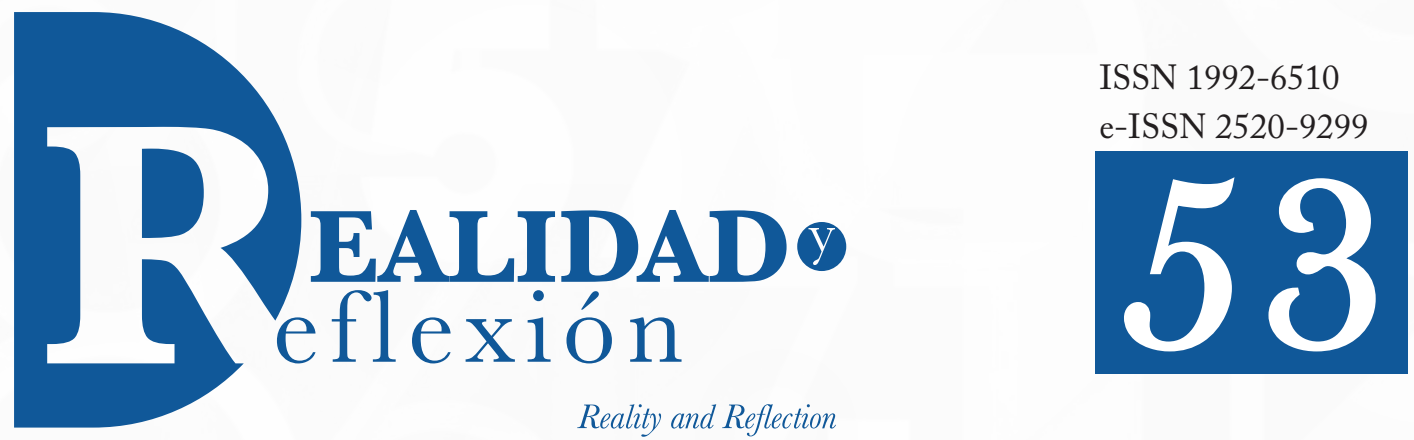

Año 21, N 53, San Salvador, El Salvador, Centroamérica. Revista Semestral Enero-Junito 2021

YEAR 21, N53, SAN SALVADOR, EL SALVADOR, CENTRAL AMERICA. SEMESTRAL JOURNAL JANUARY-JUNE 2021

\title{
AS CRIANÇAS QUE CALCULAVAM: em situação de risco social e de exclusão de aprendizagem matemática
}

\section{CHILDREN WHO COUNTED: in social risk situations and of mathematics learning exclusion}

Cristiano Alberto Muniz

Facultad de Educación Universidad de Brasilia, Brasil. cristianoamuniz@gmail.com

Recebido: 29 de junho de 2020 Aceito: 1 de setembro de 2020 DOI: $10.5377 /$ ryr.v53i53.10890

(c) (i) (2) (2) 


\section{RESUMO}

A busca pela compreensão da constituição do ser matemático como sujeito que aprende e produz sentidos subjetivos de sua capacidade em elaborar conhecimentos matemáticos encontra na categoria "sujeito que aprende", da Teoria da Subjetividade-TS, um conceito que tanto amplia quanto aprofunda as análises interpretativas da constituição matemática de crianças. A TS possibilita ampliação da compreensão do fenômeno da aprendizagem matemática para além da análise estritamente cognitiva, de análise microgenética das produções de registros matemáticos, o que realizamos nas últimas décadas apoiados na Teoria dos Campos Conceituais. Apoiados em diálogos produzidos em oficinas matemáticas lúdicas e na conversação com mães sobre suas histórias educativas, buscamos sentidos subjetivos na história de aprendizagem matemática de quatro crianças em situação de risco. Além do diálogo estabelecido ao longo das oficinas lúdicas, coletamos suas produções matemáticas. Esses registros, somados aos constantes diálogos em contexto, permitiram a análise e a explicitação de esquemas matemáticos implícitos nessas produções matemáticas e revelaram importantes elementos constituidores dos complexos processos de aprendizagem matemática. Entretanto, as análises microgenéticas não foram suficientes para o desvelamento da complexa dimensão simbólicoemocional de significação de aprendizagens matemáticas pelos sujeitos. O diálogo com as crianças e suas respectivas mães, por meio de conversão videogravada, permitiu melhor compreender a natureza das produções e seus significados para além da situação da atividade lúdica. Este artigo se limita a trazer a análise de apenas um desses casos investigados, de um menino com deficiência auditiva e que, portanto, apresenta dificuldade na organização dos algoritmos matemáticos.

Palavras-chave: crianças calculam; configurações subjetivas; aprendizagem matemática; aprendizagem e inclusão;

\section{ABSTRACT}

The search for understanding the constitution of the mathematical being as a subject who learns and produces subjective meanings of their ability to develop mathematical knowledge finds, in the category "subject who learns", of the Theory of Subjectivity-TS, a concept that both broadens and deepens the interpretive analyses of the mathematical constitution of children. The TS allows to expand the understanding of the phenomenon of mathematical learning beyond the strictly cognitive analysis, of microgenetic analysis of the mathematical records production, which we have carried out in the last decades supported by the Theory of Conceptual Fields. Supported by conversations that we obtained in playful mathematical workshops and with mothers about their educational histories, we sought subjective meanings in the history of the mathematical learning of four children at risk. In addition to the dialogue established during the playful workshops, we collected their mathematical productions. These records, added to the constant dialogues in context, allowed the analysis and explanation of mathematical schemes implicit in these mathematical productions and revealed important elements of complex mathematical learning processes. However, the microgenetic analyses were not enough 
to unveil the complex symbolic-emotional dimension of mathematical learning meaning by the subjects. The dialogue with the children and their mothers, which was video-recorded, supported a better understanding of the nature of the productions and their meanings beyond the situation of playful activity. This article is limited to present the analysis of only one of these investigated cases - a boy with hearing loss, who struggled with the organization of mathematical algorithms.

Keywords: children calculate; subjective configurations; mathematical learning; learning and inclusion 


\section{Introdução}

O estudo apresentado nesse artigo teve por objetivo pesquisar e analisar a produção de significados, sentidos subjetivos e possíveis indicadores de criatividade nas produções de esquemas mentais matemáticos de grupo de crianças em situação de risco, enquanto seres matemáticos. Apoiado na Teoria da Subjetividade (GONZALEZ REY, 2008) e na Epistemologia Qualitativa de Fernando Gonzalez Rey (GONZALEZ REY, $(2002,2014)$, buscamos alargar nossas análises das produções de esquemas mentais em atividades lúdicas para além da Teoria dos Campos Conceituais de Gérard Vergnaud (1998), procurando descrever e compreender, por um processo interpretativo e de teorização, as produções de registros matemáticos de crianças em situação de exclusão social.

Para tanto, nos apoiamos na categoria "ser matemático" que é proposta a partir da posição epistemológica de que a aprendizagem matemática escolar não deve se constituir na assimilação mecânica de procedimentos operatórios como prevalece hoje em nossas escolas. A epistemologia que sustenta o conceito de "ser matemático" (MUNIZ, 2001) considera o sujeito que aprende como efetivamente produtor de conhecimentos e saberes matemáticos, dentro ou fora da escola, em situação de sucesso ou de fracasso escolar. Ou seja, mesmo em situação de insucesso e exclusão há aprendizagens, pois todo sujeito aprende.

Essa perspectiva epistemológica reconhece que a aprendizagem e a construção de saberes matemáticos não são lineares, tampouco isentas de erros. Os caminhos tortuosos, as aparentes involuções e os erros na busca de matematização podem dar acesso ao educador, assim como ao pesquisador, a compreensão dos complexos processos (conceitualização, construção e validação de procedimentos, desenvolvimento da linguagem e registros, argumentação e prova) que determinam a aprendizagem matemática, não sendo válida, portanto, nessa perspectiva, a postura de validar uma produção de um ser matemático como universalmente válida e certa, enquanto verdade matemática. Afinal, o que nos interessa é a estruturação (mesmo que esta seja sempre parcial) e a compreensão (o que requer um esforço interpretativo) da construção de conceitos matemáticos (conceitualização) e de procedimentos resolutivos, mesmo que incompletos, sem valor para generalização ou, ainda, que matematicamente errados, mas de alto valor para a formação dos pensamentos do ser matemático em início de constituição.

Teoricamente, o ser matemático é aquele que aprende e que desenvolve processos cognitivos, esquemas mentais próprios para superação de dificuldades, de enfrentamento de desafios, que produz processos resolutivos para situações-problema matemáticas, que acredita em sua própria capacidade de gerar novos procedimentos para situações inéditas. Mesmo que tais processos matemáticos, geridos pelo sujeito para resolver problemas, tenham validade apenas local, sem valor geral ou científico, esses processos podem revelar capacidades cognitivas articuladas à construção de conceitos e procedimentos. Em análises microgenéticas, podemos explicitar os esquemas mentais (VERGNAUD, 2009) que dão sustentação à estruturação do pensamento matemático presente na atividade matemática da criança 
ou jovem, desvelando conceitos, hipóteses, procedimentos, lógicas próprias do indivíduo que busca elaborar uma solução de uma situação dada, assim como as estratégias e valores de sua validação.

A negação da existência ontológica de um ser matemático em cada um que aprende e se desenvolve é característica de contextos educacionais em que os conceitos de certo e errado das produções matemáticas de crianças e jovens estão colocados de forma equivocada. No contexto da aprendizagem matemática, na busca da contribuição do desenvolvimento das capacidades matemáticas, mais importante que julgar uma produção estritamente como certa ou errada, seja em relação a seu valor prático ou científico, deveria o educador pautar sua ação pedagógica pela valorização dos processos de aprendizagem que requerem a busca da compreensão dos processos.

Assim sendo, na perspectiva da categoria de ser matemático, o educador matemático (aquele que promove mediação ou intervém nos processos de aprendizagem matemática) não deve se limitar, no início da aprendizagem de novos conceitos-procedimentos, a julgar a validade dos processos de produção matemática em face do conhecimento científico universalmente sistematizado. Cabe ao professor mergulhar num esforço de interpretação das lógicas inerentes às produções matemáticas daquele que está em processo de aprendizagem, num importante deslocamento epistemológico: não julgar a produção da criança apoiado nos algoritmos matemáticos ortodoxos, medindo o quanto a produção da criança se aproxima ou se distancia das verdades matemáticas postas como imutáveis. Deveria cada educador buscar compreender e participar da construção dos conceitos e procedimentos que, no desenvolvimento daquele que aprende, revelam-se instáveis, provisórios, não validados, com veracidade e validade apenas locais e circunstanciais. Captar, compreender, valorizar, socializar e institucionalizar os caminhos, descaminhos, atalhos, retrocessos, antagonismos, provisoriedade, recursividade. Estes foram objetivos nosso (MUNIZ, 2009) ao analisar os processos de produção de registros matemáticos de crianças consideradas em situação de dificuldade pela escola. Das produções matemáticas, em ação, daquele que aprende são formas de considerar que cada criança e cada jovem, na realização de tarefas matemáticas, são seres matemáticos em plena mobilização de saberes construídos ao longo de suas histórias sócio-cognitivas-emocionais e sociais, tendo sempre a cada novo desafio, de rever conceitos e procedimentos, fazendo evoluir seus conhecimentos para dar conta de novas e mais desafiantes situações-problema.

Contribuições da Teoria dos Campos Conceituais -TCC do psicólogo cognitivista, didata e matemático francês, Gérard Vergnaud (1994), despertam para um novo olhar para as produções matemáticas das crianças: lógicas e verdades localmente validadas. Se assumirmos que, no processo da aprendizagem, as construções de saberes matemáticos são apenas localmente validados, isso acaba por nos revelar o quanto é medíocre a escola que se limita a atribuir à produção matemática escolar somente "certo" ou "errado", perdendo a oportunidade de compreender, individualmente, os processos de atribuição de significados em relação àquele que está a aprender. 
Na intenção de revelar uma capacidade intelectual para processos de matematização presentes na escola dos quais somos testemunha, buscamos, discutir acerca da estreita relação entre fazer matemática e desenvolvimento da inteligência nos anos iniciais do ensino fundamental, quando crianças consideradas em situação de dificuldade na aprendizagem matemática, em nossas análises, acabam por nos revelar uma sagacidade cognitiva que nos leva a considerar a presença de processos inteligências geralmente eliminadas do processo curricular escolar.

Portanto, o objetivo deste estudo é analisar a produção de significados, sentidos subjetivos e possíveis indicadores de criatividade nas produções de esquemas mentais matemáticos de grupo de crianças em situação de risco.

Nosso desafio foi promover tanto uma ampliação da categoria ser matemático como sujeito produtor de sentidos subjetivos na aprendizagem matemática, quanto ampliar a compreensão a respeito dos fenômenos que levam esse sujeito a produções diversas e complexas de configurações subjetivas expressas em relações com os objetos e as atividades matemáticas. Essa ampliação da busca da compreensão do ser matemático enquanto sujeito, hoje desconsiderada tanto no campo da psicologia cognitiva quanto no contexto didático-pedagógico.

Compreender as produções de conceitos e teoremas matemáticos, a autoimagem para a aprendizagem, a configuração de suas emoções frente à matemática pode ser plausível a partir da construção de espaços e instrumentos de diálogo com os sujeitos que vivem a produzir, a testar, a rever, a reconfigurar sua visão dos papéis da matemática para seu desenvolvimento humano e na relação com seu mundo social e cultural.

Figura 1: A constituição do ser matemático e as produções de sentidos subjetivos:

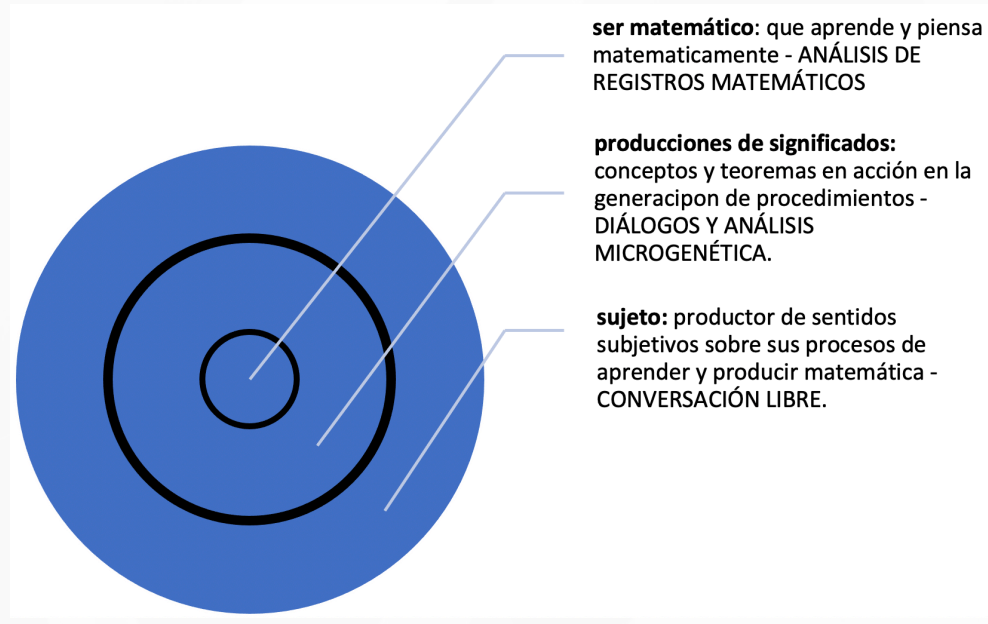

Fonte: produzido pelo próprio autor 
Portanto, hipotetizamos que a produção matemática do ser matemático é determinada, dentre muitos fatores, pela sua condição ontológica de sujeito, ativo nos processos de aprender, de aprender matemática, em que o sistema simbólico-emocional define opções, posições, caminhos, intensidade de adesão à atividade, autoimagem e autoconfiança para superação de desafios matemáticos e mais, participa determinantemente se sua emocionalidade na relação com os objetos matemáticos, uma emoção que qualifica os processos de produção matemática, de aprender matemática e, na visão do ser matemático, de si mesmo, como produtor de conhecimentos e sentimentos.

\section{Método e procedimentos metodológicos}

Valorizar as produções requer mudanças nas nossas concepções de matemática, de sua produção, de sua aprendizagem, de seu valor social e formativo. Mudanças muitas vezes não elementares, pois vem de encontro a nossas formações acadêmicas. Todavia é justamente o debruçar-se sobre tais produções, o diálogo com as crianças autoras, a troca com colegas que nos permitiram uma discussão mais ampla de ordem epistemológica que trata da escola como espaço de produção de saberes em não apenas de consumo de conhecimentos escolares.

Na perspectiva da pesquisa qualitativa defendida por González Rey (2002, 2014), assumimos desde o início que pesquisar é produzir conhecimento, e que é reflexo das formas e procedimentos em que se constituem as relações entre o pesquisador e os sujeitos produtores de informação. Neste sentido, buscou-se nos procedimentos dar valor e captar produções e sentidos dos diferentes sujeitos, com o recurso essencial de variedade de procedimentos de captação das ações, registros, pensamentos, sentimentos presentes ao longo de suas produções matemáticas.

Assim, nosso foco está apoiado em González Rey, na busca do confronto de diferentes produções obtidas por intermédio da diversidade de recursos e procedimentos, onde o diálogo entre pesquisador e sujeitos matemáticos, foi a coluna vertebral do método, uma vez que os sentidos subjetivos das produções, aliados à própria história sócio-educativa de cada um, com suas experiências dentro e fora da escola, relatos das próprias crianças e pelas suas mães, com conversações livres vídeo gravadas, após 10 meses de convívio em oficinas de matemática lúdicas, puderam permitir a captação mais qualitativa das produções matemáticas e seus sentidos subjetivos para o sujeito e seu grupo engajados na atividade.

As muitas e possíveis posturas ante o objeto de investigação, a construção conceitual, epistemológica e teórica, assim como a postura política diante do campo de investigação, em especial, perante a escola e seus agentes, determinam certamente a natureza do conhecimento em produção, bem como a constituição da relação entre a academia e a universidade.

Dentre as múltiplas possibilidades de conceber a pesquisa, objetivando compreender a natureza epistemológica da dificuldade na aprendizagem matemática na escola, buscamos compreender os 
processos de aprendizagem, especificamente da matemática escolar da escola fundamental, articulando a análise microgenética com processos metacognitivos. Isto tem requerido o desenvolvimento da pesquisa-ação com permanência constante no espaço escolar e o convívio profundo e fecundo com alunos e professores.

O estudo foi realizado durante 10 meses, ao longo do ano de 2014, construindo uma oficina de matemática lúdica, para um grupo de crianças em situação de risco que participam regularmente do Centro de Vivências do CRAS- Centro de Referência de Ação Social de Alto Paraíso de Goiás. Os sujeitos participantes da investigação são crianças dos anos iniciais do Ensino Fundamental brasileiro, 11 crianças, entre 6 a 11 anos, com escolaridade entre $1^{\circ}$ e $5^{\circ}$ ano do ensino fundamental em escola pública de Alto Paraiso de Goiás, sendo 6 meninas e 5 meninos. São característica do grupo participante:

- Moradores do interior do estado de Goiás- Brasil.

- Em situação de risco, provenientes de famílias de baixa renda.

- Nenhum convive com o pai biológico.

- Alunos dos anos iniciais do ensino fundamental em escola pública.

- Frequentam o Centro de Atividades do CRAS (Centro de Referência de Assistência Social), que oferece acompanhamento dos deveres de casa, oficinas como teatro, circo, capoeira, e no ano de 2014, Oficina de Matemática Lúdica. A inscrição nas oficinas é espontânea, de acordo com o interesse. Além das atividades, o CRAS fornece lanche diário para as crianças participantes.

- Mais de $90 \%$ das crianças as mães não têm o ensino fundamental completo. Atuando no comércio, com serviçais em pousadas ou cada de família. As mães se revelam muito dedicadas à educação de suas crianças, procurando estimular para os estudos e realização de atividades que favoreçam o desenvolvimento de habilidades variadas. Todas acompanham de perto a vida escolar das crianças, tendo presença constante na escola e nas atividades do Centro de Atividade

\section{Resultados e discussões}

O estudo foi realizado com um grupo de onze crianças em processo de escolarização, dos anos iniciais do Ensino Fundamental, todas em situação de risco social, na região da Chapada dos Veadeiros, importante APA- Área de Proteção Ambiental do Centro-Oeste brasileiro. O grupo era atendido pela Secretaria de Ação Social, no contraturno da ida à escola, onde criamos, por meio da pesquisa, um ambiente ludomatemático, com atividades, materiais e jogos que favoreciam aprendizagens matemáticas previstas 
no currículo escolar. Neste texto trazemos o caso do Rochinha ${ }^{1}$ (pseudônimo), por se tratar de um menino que, além de estar em situação de risco social, é deficiente auditivo, o que dificulta tanto sua compreensão dos conceitos e procedimentos matemáticos, quanto apresenta dificuldade de comunicação dos pensamentos matemáticos na escola. Há apontamentos em seu registro no projeto municipal que Rochinha tem dificuldades escolares, sobretudo na aprendizagem matemática.

\section{Rochinha, na busca da alfabetização matemática}

Rochinha, com 7 anos de idade, frequentando o $2^{\circ}$ ano de escolaridade, desde o início das atividades revela-se uma criança, alegre, interessada nas participações, demonstrando grande curiosidade pelos materiais lúdicos e atividades dos jogos matemáticos. Mesmo não sendo o mais novo do grupo, é o que tem a menor estatura. Gosta muito de realizar jogos corporais, de lutar, correr, sempre nos recebe com belo sorriso, desde o momento de nossa chegada a cada tarde.

Faz-se necessário destacar que as atividades matemáticas que permeiam os jogos são de graus de dificuldade gradativa, ou seja, conforme o jogo avança, as dificuldades nas resoluções de problemas, os contextos e a ordem de grandeza dos números envolvidos aumentam a cada rodada.

Sempre presente nas tardes das quintas-feiras no Centro de Atividades, muitas vezes, observamos que sua alegria pela participação e sua curiosidade acabam sendo substituídas por um isolamento no canto da sala, com a recusa de continuar a participar e com cara fechada. Tal atitude nos instiga, e procuro me aproximar dele, entretanto ele se nega a falar o porquê da recusa na participação.

Rochinha evita qualquer aproximação ou tipo de ajuda, não querendo dizer o porquê, deixou de participar, tampouco deixa transparecer ao grupo suas dificuldades. Nega mesmo qualquer aproximação de sua irmã, participante do grupo, mais velha, Tiana com 10 anos e frequentando o $5^{\circ}$ ano do EF.

As atividades matemáticas não apresentam linearidade nem de conteúdos, de conceitos, tampouco de dificuldades nos jogos. Como o grupo é bem heterogêneo, buscou-se no planejamento e desenvolvimento uma variação dessas atividades, favorecendo a mobilização de conceitos de formas recursivas, procurando envolver um mesmo conceito em diferentes jogos, assim como variar o grau de dificuldades dentro de um mesmo jogo.

No decorrer das atividades, com aproximação gradativa, ganho a confiança de Rochinha e vemos surgir a construção de uma relação dialógica, quando pudemos aos poucos tomar conhecimento de seus processos de aprendizagem, seus sentimentos em relação à matemática, e como se percebe nessas

$1 \mathrm{O}$ nome da criança fictício buscando preservar a identidade das crianças participantes. Os nomes são escolhidos tendo por base traços da personalidade de cada participante: Rochinha, o cineasta e fechado. 
relações favorecidas pelas atividades lúdicas. Interessante ressaltar que a explicitação das potencialidades, dos limites e de suas dificuldades é revelada tão somente no desenvolvimento dos jogos, dos registros, das trocas presentes na atividade, sendo que, em momento algum fomos procurados por ele para colocar suas dúvidas, dificuldades ou mesmo, como fizeram algumas crianças (sobretudo em relação à divisão), demandando que, no Centro, trabalhássemos conteúdos escolares com os quais estão tendo dificuldade ou curiosidade. Em momento algum levou dever de casa para realizar no Centro.

Essas dificuldades observadas ao longo das atividades realizadas por Rochinha serão agora apresentadas e analisadas, mas sempre levando em conta o contexto do jogo matemático, as exigências de conceitos, procedimentos e registros. Após discutirmos uma série de produções de Rochinha, vamos trazer um pouco da sua própria fala sobre seus processos subjetivos, uma vez que, em seus registros, como veremos, há fortes indicadores de configurações subjetivas no complexo processo de sua aprendizagem matemática. Num momento posterior, damos voz à mãe da criança, para situar histórica e afetivamente o desenvolvimento dele, o que pode nos ajudar, por meio da conversação, confirmar ou não hipóteses sobre os processos de configurações subjetivas.

\section{Estrutura do número: leitura, compreensão e registro}

Como foi dito, há uma percepção de nossa parte, desenvolvida no trabalho empírico, que há forte tendência de evasão da atividade, quando Rochinha se defronta com números de maiores ordens ou quando há na atividade lúdica proposta de leitura, interpretação, construção de procedimentos operatórios com registros que requerem a necessária compreensão da estrutura do número, mesmo que este seja um número natural. Foram muitas atividades que mobilizaram a estrutura do número e suas consequentes interpretações e leituras, dentre elas: bingo, jogo do tapetinho, jogo da vendinha, corrida, jogo da memória, dentre muitos outros. Mas foi no jogo das fichas escalonadas, aplicados no dia 13 de novembro que pudemos efetivamente constatar o nível de dificuldade do Rochinha quanto à compreensão e produção de significados da estrutura do número.

Ao trabalharmos com as fichas escalonadas, pudemos ver, em situação de necessidade de leitura, interpretação e comparação que números maiores que 100 impunham grandes dificuldades, tal como 789 e Rochinha lê: "setenta e oito... nove" ou ainda 1994 como "dezenove noventa e quatro" revelando que possivelmente sua alfabetização matemática tenha ficado restrita a uma centena exata. Entretanto, ele não se recusa a ler e a comparar e produz um esquema mental que está sustentado em suas construções prévias: lê os números de dois em dois dígitos, limitando-os, em sua composição, às dezenas. Há momento em que sua leitura é “cento e quarenta e cinco... oito" para 1458.

Na conversa com sua mãe, durante o processo, ela afirma que nunca a escola havia chamado a atenção para tal problema, mesmo ela estando quase que diariamente presente na escola e acompanhando as tarefas. Cabe desde já informar que Rochinha reprovou o ano letivo em 2014, no segundo ano de escolaridade, em pleno ciclo de alfabetização, pois não conseguia realizar as atividades matemáticas escolares. 
A atividade lúdica com as fichas escalonadas ajuda muito as crianças a perceber as estruturas do número e acabam por revelar suas hipóteses sobre tais estruturas e consequente leitura e escrita interpretativa das quantidades. Como vemos a seguir no registro de Rochinha no jogo das Fichas Escalonadas, acabamos por compreender um pouco mais de suas produções:

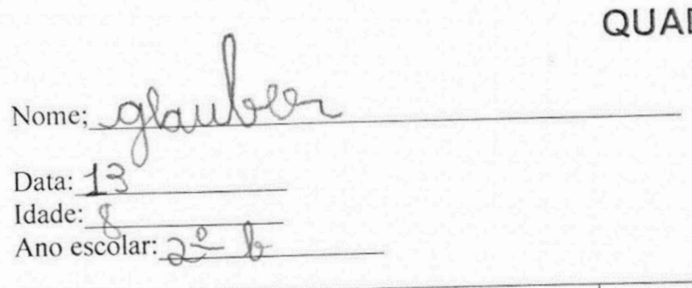

\begin{tabular}{|c|c|c|}
\hline Número & Composição & Escrita \\
\hline 124 & $100+20+4$ & cento e vinte e quatro \\
\hline $\begin{array}{l}34 \\
77\end{array}$ & & Asitinto , Set \\
\hline$\frac{\frac{1}{7}+7}{8408}$ & $\frac{70+}{800+5}$ & vitos entos e cinco \\
\hline 9003 & $000+40+0$ & \\
\hline
\end{tabular}

Figura 2: Decomposição e escrita dos números revelando a escrita como se lê

No quadro número-composição-escrita, sendo o número dado pelo pesquisador, a composição dada pelo uso de fichas e a escrita uma composição a partir das leituras das fichas utilizadas. Ao solicitarmos no jogo a composição com as fichas o número 848, escreve "8408", ou seja, pela nossa interpretação "oitocentos e quarenta e oito", ou seja,

"oitocentos e quarenta $\rightarrow 840+$ oito $\rightarrow$ 8", sintetizando:

$840 \rightarrow$ oitocentos e quarenta

$8 \rightarrow$ oito, assim, temos "oitocentos e quarenta e oito" $=8408$.

Tal análise interpretativa é reforçada na linha seguinte com o próximo número, 903, ou seja, novecentos e três, e sua produção, a qual acaba por abandonar fica sendo:

$900 \rightarrow$ novecentos

$3 \rightarrow 3$, assim temos $9003=$ novecentos e três. 
$\mathrm{Na}$ atividade com as fichas escalonadas, para Rochinha, a composição do número e consequente escrita-leitura implica inclusive a não sobreposição das fichas de forma a produzir 903 e fica apenas com a justaposição permanecendo a ficha 900 justaposta à ficha 3, o que gera 9003, sendo, de acordo com a hipótese de escrita de Rochinha e em acordo com sua escuta, "novecentos e três" $=900+3$.

Essa análise e hipóteses ganham força teórica e lógica quando trazemos a fala de Maria, mãe de Rochinha, e da própria criança quando ela faz críticas às posturas da professora diante de suas dificuldades, culminando, inclusive na reprovação no ano letivo de 2014.

Veremos agora que essa questão da forma de apropriação da estrutura do número pelo Rochinha implica consequências, também nos processos de geração de procedimentos operatórios e, mesmo, dificultando a compreensão dos algoritmos ortodoxos impostos pela escola desde o processo de alfabetização.

\section{Estrutura do número: implicações para produção e registros de procedimentos operatórios}

Além da questão mais estrita da produção de escrita e leitura interpretativa dos números, constatamos, em nossas análises interpretativas das suas produções de registros matemáticos, que a não apropriação devida da estrutura dos números por Rochinha, acaba por dificultar a produção de procedimentos eficientes.

Ao longo do projeto, foram muitas as situações em que os jogos requereram das crianças participantes a produção de procedimentos operatórios, como na trilha, no mercadinho, no tapetinho, no jogo dos pratinhos com divisão, dentre outros. Assim, nas produções a seguir, nas quais temos as operações 1.847 + 2.356 e 145 + 382, vê-se que mesmo com números maiores, mas com mesmo número de ordens, como na adição, Rochinha não teve dificuldade, pois o posicionamento espacial é mais evidente, acabando por ficar ordem abaixo de ordem, levando ao sucesso do sujeito.

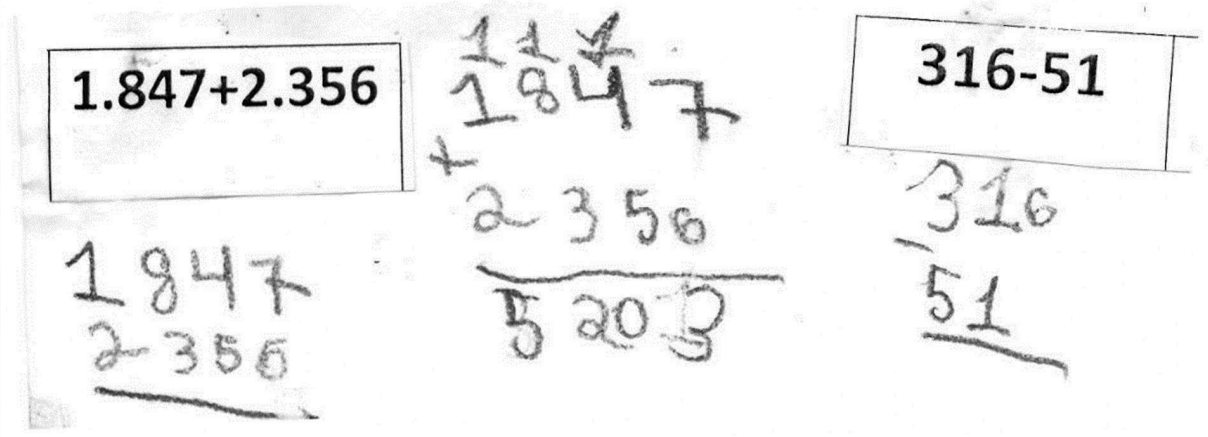

Figura 3: Questão da espacialidade influenciando o posicionamento e construção de procedimentos 
Entretanto, no caso de 316- 51, uma operação com menor ordem de grandeza (não discutiremos agora o fato de a mesma implicar um desagrupamento decimal) vemos a dificuldade de localização espacial do Rochinha quanto aos dígitos, acabando por ficar o 5 abaixo das 3 centenas, o que inviabiliza realização da operação, uma vez que dá a impressão de que fará 300 - 500. Assim, Rochinha abandona-a e não marca o resultado na cartela do bingo numérico.

A mesma dificuldade de orientação espacial e posicional quanto aos dígitos e suas ordens, ocorre no jogo do Bingo. Nesse jogo, são distribuídas operações em uma folha quadriculada, nas quais cada jogador deve recortar, operação a operação. Aí o pesquisador ao longo do jogo, uma por vez, sorteia uma operação que deve ser colada numa folha fornecida no jogo pelo pesquisador. Ao resolver na folha a operação, o jogador tenta identificar esse resultado em sua cartela. Caso tenha, marca o número com um "X".

Num momento do jogo, Rochinha ao realizar $279+15$, tem dificuldade nos posicionamentos das ordens, o que o leva a totalizar 942, perdendo a chance de marcar um ponto, pois esse total não se encontra nas cartelas (observamos que não achar um número na cartela, pode, para uma criança em jogo, interpretar como um possível erro em sua conta, mas isto não ocorre a Rochinha):

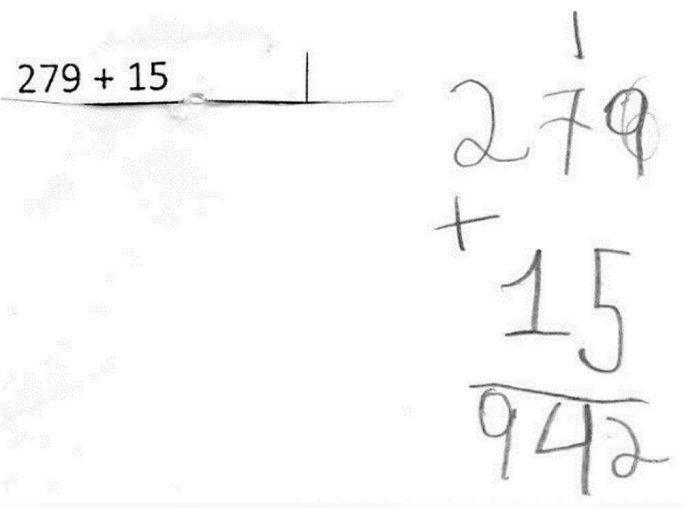

Figura 4: Questão da dificuldade de espacialidade como obstáculo na produção matemática

Vemos o esquema mental explicitado em forma de teorema em ato (VERGNAUD,2009). Soma 9+5 = 14, ficando 4 unidades, promovendo uma dezena e somando as dezenas, totalizam 9 dezenas e aí, aparece novamente a questão espacial. Colocando as duas centenas que sobraram à direita do total e não à esquerda, revela não ter conhecimento de que este “dois" é de centenas. Dessa forma, a questão espacial de posicionamento articula-se e é somada à questão da não compreensão de números a partir de 200. Isso ocorre novamente quando um número tem centenas e o outro não. $\mathrm{Na}$ mesma folha de produção de registros, vemos outro caso, no qual ambas as parcelas têm centenas e neste, Rochinha não apresenta qualquer dificuldade. 
Nesse ponto de análise e produção de interpretação, cabe-nos a pergunta: até que ponto Rochinha tem consciência da natureza de suas dificuldades que estão necessariamente articuladas à questão posicional e aos significados da estrutura dos números em ordens e classes, assim como sua compreensão entre valores posicional e decimal. Nessa última produção vemos que a noção de valor decimal se revela bem avançada, ficando nosso indicador de dificuldade direcionado para a questão posicional.

Um fato importante revelado no processo interpretativo é que, desde o início das atividades, Rochinha procura produzir respostas, engaja-se numa atividade cognitiva importante, não abrindo mão de seu direito em participar e produzir registros matemáticos, segundo suas capacidades e potencialidades, não negando a existência de dificuldades. Isso revela que, nas atividades em que abandona o jogo, isola-se e fica visivelmente aborrecido, pode ser reflexo de uma tomada de consciência de que as situações não podem mais ser controladas por ele e não se vê capaz de produzir uma solução, pois os valores a partir de um momento do jogo estão além de seu nível de aprendizagem, sobretudo em relação à estrutura dos números.

Portanto, o diálogo para a interpretação e compreensão desses processos complexos e não lineares requerem, coadunando com a perspectiva da Epistemologia Qualitativa de Gonzalez Rey, a constituição de um ambiente permeado pelo diálogo entre sujeito e pesquisador, na busca de elementos de interpretação que favoreçam que a produção de conhecimento produza informações as mais próximas possível desse processo psicológico que o próprio sujeito epistêmico não tem consciência. Assim, a articulação da fala do sujeito com os registros produzidos (assim como a explicitação de esquemas mentais), pode fornecer importantes ferramentas de análise para explicitação de produção de significados e sentidos subjetivos.

Uma diferença de ordem epistemológica deste estudo para os anteriormente realizados no campo da educação matemática, é que ao nos apoiarmos na Epistemologia Qualitativa, não mais nos limitamos apenas à explicitação dos esquemas mentais (VERGNAUD, 2009) na produção de registros dessas crianças, buscando ampliar as fontes de produção de informações para nossas interpretações e busca de indicadores. A partir da identificação dos esquemas explicitados em forma de conceitos e teoremas em ação (VERGNAUD, 2009), buscamos articular a compreensão dessas produções à percepção mais ampla da própria constituição do sujeito, enquanto sujeito social e emocional, entrelaçando esses conceitos e teoremas à própria compreensão de sua história constitutiva.

\section{Fala de Rochinha enquanto sujeito matemático}

Assim, partimos agora para a fala do próprio Rochinha que nos revela elementos importantes de sua própria imagem constitutiva e nos faz melhor compreender suas produções matemáticas e o complexo processo de aprendizagem matemática e desenvolvimento humano. No início da conversação videogravada, Rochinha fala de suas preferências na escola: 


\section{(...)}

Pesquisador: Tá. E na escola o que você gosta na escola?

Criança: Eu gosto de ir pro recreio.

P: Do recreio. O que tem de legal no recreio que você gosta?

$\mathrm{C}$ : Os brinquedos.

P: Quais brinquedos?

C: Tem um grandão e aí a gente sobe nele e fica lá em cima.

P: E fora do recreio o que você gosta?

C: Matemática.

P: Ah gosta? Só porque eu tô aqui?

C:Não.

P: Não? Você sempre gostou de matemática?

C: Antes não.

P: Antes não? Como é que você começou a gostar de matemática?

C: Quando você me deu aula.

P: Ah é? Foi aula que eu dei?

C: Foi.

Os prazeres estão fora da sala de aula, estão na recreação, na "não aula". A princípio, o gosto pela escola não está vinculado aos conteúdos de componentes escolares. Quando provocado para dizer sua preferência, ele cita imediatamente a Matemática, mas uma relação afetiva que surgiu somente no ano passado por causa das experiências vivenciadas no Centro em função do nosso projeto. Assim podemos constatar inicialmente que, de alguma forma, as atividades lúdicas no Projeto influenciaram a relação com a área de conhecimento, o que foi fundamental para o delineamento das estratégias educativas no processo.

Interessante notar que Rochinha vê a experiência como "aula", mesmo que as atividades não ocorriam em sala de aula, não havia quadro nem livro, caderno formal, tampouco avaliações, mas desenvolvido sempre por meio de jogos e atividades lúdicas. Sobre sua visão do que era proposto e o que desenvolvia durante as atividades ele coloca:

P: Ah foi? E lá no CRAS, lá no Centro o que você fazia de matemática?

C: Brincava.

P: Brincava de quê? Que tipo de brincadeira que era?

C: Tinham uns carrinhos aí passava nos números, brincava de uns negócios que no último ganhava pulseira.

P: Mas era só por causa do prêmio que você gostava das aulas de matemática?

C: Não. 
Assim, no Centro, a visão da realização da atividade matemática está ancorada no brincar e na premiação. $\mathrm{O}$ brincar que caracteriza as vivências matemáticas no Centro é precisamente o elemento de prazer experimentado na recreação dentro da escola. Quanto ao questionamento de seu prazer por certas atividades ser em função de poder ganhar certos prêmios em jogos, Rochinha nega, ou seja, possivelmente o prazer está associado com a atividade e experiência vivenciada em si. Além disto, levantamos a hipótese: se a afetividade não estaria associada também ao fato de a experimentação, nessas atividades propostas e mediadas, favorecer a superação de desafios e dificuldades, revendo seus processos de aprendizagem matemática. Assim perguntamos como foi, neste mesmo período, a matemática na escola:

P: E você como era o ano passado a matemática na escola?

C: Foi bom.

P: Na escola como é que foi, com é que era naquela escola que você estava? Fala um pouquinho.

C: A professora sempre saía da sala, ela ia pra outra escola ficava lá.

P: E você ficava fazendo o que dentro da sala?

C: Ficava copiando.

P: Ela passava no quadro, explica aí como é que era.

C: Ela passava no quadro e dava uma tarefa, primeiro tinha que fazer a tarefa e depois copiar do quadro. Aí ela ia e saí e a gente ficava com dificuldade e aí a gente esperava ela chegar.

P: E quando ela chegava o que ela fazia?

C: Ela explicava.

P: E você entendia?

P: Sempre?

C: Sim.

P: Tá. Você gostava de fazer os deveres de matemática o ano passado naquela escola?

C: Sim.

P: Qual era a tua maior dificuldade de matemática o ano passado? Você falava não essa eu tinha dificuldade, quando chegava nessa parte você falava ai meu Deus. O que era?

C: Eu cheguei e falei, a não essa atividade, não! Aí ela ia lá, pegava o caderno e abria aí ela passava e explicava.

C: Na hora que tinha que copiar e não saía pro recreio.

Foi surpresa para nós a resposta inicial de que a experiência escolar com a matemática ter sido boa, ainda mais considerando que foi reprovado neste ano letivo justamente por causa da matemática. Quando instigado a falar mais, acaba por expressar que as atividades escolares sintetizavam na realização de cópias do quadro e destacou a permanente ausência da professora da sala de aula. Mesmo acompanhando sua vida escolar, sabendo da alta desmotivação pela escola no ano passado, ele afirmou que gostava das atividades e que entendia as explicações, entretanto, a professora não se fazia presente ao longo das atividades, permanecendo fora de sala, voltando apenas para colocar a resposta certa no 
quadro. A não saída para o recreio era utilizado pela professora como forma de controle da turma na realização das atividades. Essa ausência da professora do ano passado na sala de aula fica ressaltada em outra fala:

P: Tá. E esse ano como é que está?

C: Bom.

P: Por que melhorou esse ano?

C: Porque é outra professora e ela explica mais ainda, ela mantém na sala ela só sai de vez em quando. Aí ela fica toda hora na sala.

Quando questionado ao longo da conversação sobre o que a professora do ano passado deveria mudar, ele reforça essa questão do abandono da sala de aula:

P: Se você encontrasse com a professora do ano passado, da outra escola, se você fosse chegar e dar um conselho pra ela como é que ela podia melhorar a aula dela. O que você falaria pra ela?

C: Que ela tem que melhorar as continhas de matemática, português e só.

P: Só.

P: E como poderia melhorar as continhas de matemática?

C: Ela ficasse dentro da sala.

P: Que ela ficasse com vocês na da sala. Fazendo o que dentro da sala?

C: Explicando.

P: Explicando...

C: E de vez em quando ela saísse.

Quanto às suas lembranças acerca das maiores dificuldades matemáticas temos:

P: Mas você não lembra qual era a matemática que você tinha dificuldade?

C: Não.

P: Trabalhar com números, saber escrever os números?

C: Sim.

P: Ler os números?

C: Sim.

$\mathrm{P}: \mathrm{E}$ as operações você sabia?

C: Mais ou menos.

P: Quais operações que você sabia mais?

C: Português.

P: Operação de matemática?

C: Era... eu esqueci.

P: Ah, esqueceu? Você gostava de somar? 
C: Ahã?

P: Adição, continha de mais?

C: De mais era mais fácil pra mim.

$\mathrm{P}: \mathrm{E}$ de menos?

C: Mais ou menos.

$\mathrm{P}: \mathrm{E}$ tinha de divisão?

C: Tinha.

P: E o que você achava da divisão?

C: Muito difícil.

Inicialmente, Rochinha diz não lembrar quais eram suas dificuldades em Matemática, mas com o questionamento do pesquisador, ele acaba por revelar que o trato com os números era sua dificuldade central, como vimos nas análises de suas atividades. Tanto que ao ser perguntado sobre as "operações que mais sabia" ele acaba por se referir ao "Português", mas quanto às operações matemáticas, nem sabia dizer quais eram. Entretanto, sua facilidade era na adição, sendo as demais difíceis, sobretudo a divisão, o que é reforçado nas análises de suas produções. O esquecer pode ter dois sentidos: (1) esquecer, pois são processos sem sentidos, sem possibilidade de tecer uma lógica de explicitação das dificuldades: e (2) esquecer algo que remete ao dissabor.

P: E lá no Centro de atividade teve divisão? Você lembra? Que tinham os pratinhos?

C: Tinha.

P: E aí como é que foi lá no Centro?

C: Foi bom, aí tirava os pratinhos e entregava, aí fazia dupla.

P: Aham...

C: Um ia com um, o outro ia com outro e outro ia com outro.

$\mathrm{P}$ : E lá você conseguiu?

C: Aham.

Já no Centro, as atividades de divisão não revelam a mesma dificuldade, uma vez que elas se apoiam na construção conceitual e no desenvolvimento de procedimentos com apoio em representações concretas, o que favorece articular o repartir com a contagem partilhada igualmente em pratinho, com construção gradativa de significados, mesmo que esses processos não o levassem à articulação com a estrutura formal e abstrata da divisão exclusivamente enquanto algoritmo escrito. Entretanto, ele revela que nas experiências realizadas no Centro pode avançar no que diz respeito a sua maior dificuldade, ou seja, o trato com os grandes números:

P: A página 21, você consegue achar no livro a página 21?

C: Sim.

P: E página 425? 

C: Consigo.
P: Ah, já consegue.
P: E se for 1426?
C: Não conseguia não.
P: Não. E hoje você consegue?
C: Sim.
P: Achar o 1000 ?
C: Sim.

Hoje ele pode, sobretudo depois de trabalhar em jogos com as fichas escalonadas, efetuar a construção de significados com números com 3 ou mais ordens, o que era inclusive dificultador para o desenvolvimento de procedimentos operatórios.

\section{Quem é Rochinha para Maria... Visão maternal, reveladora}

A visão da mãe aqui é importante no sentido de que ao longo da conversação, novos elementos interpretativos e hipóteses podem ser revistos ou confirmados, a partir de elementos psicológicos trazidos por aquela que tem uma visão global do desenvolvimento do nosso sujeito. Ressaltamos que a fala da mãe retrata somente uma imagem que ela constrói do sujeito, nem sempre correspondendo à realidade.

Maria não tem formação nem do Ensino Fundamental, mas é trabalhadora, lutadora pela manutenção dos filhos e, bem mais que isso, busca garantir-lhes direitos que lhe foram negados em sua infância e juventude, sempre acompanhando o desenvolvimento dos filhos e estimulando-os aos estudos.

Sua fala inicial traça a visão que tem do Rochinha como:

P: Quem é pra você o Rochinha?

M: Ah, uma criança muito especial, meu filho é um doce. Ele tem às vezes alguns tiuchi, mas é maravilhoso. É inteligente, trabalhador, gosta de fazer as "tarefinhas" dele direitinho, é cuidadoso.

Esforço e motivação são pontos de destaque na caracterização de Rochinha, sendo que não interpretamos as "tarefinhas" como necessariamente atividades escolares, mas atividades de forma geral. Assim vemos uma criança que gosta de apresentar resultados e esforço.

Quanto ao aspecto "inteligência” pedimos que Maria explicitasse essa compreensão:

P: Você fala que ele é muito inteligente, né? Como que você percebe essa inteligência dele?

M: Porque tudo que ele pega ele faz sozinho, consegue desempenhar bem as coisas que ele começa. Esse ano graças a Deus ele não tá com dificuldade nenhuma, tudo pra ele tá mais 
fácil. Tudo que ele pega pra fazer ele faz sem muito: - "Mãe me ajuda aqui! Fulano vem cá! "Não, ele tá desempenhando bem o papel de filho e de aluno, na sociedade tá indo bem, graças a Deus.

Assim a inteligência é expressa por Maria associada à autonomia, à sua capacidade de realização das coisas, resolvendo por si os desafios inerentes às atividades. Mas a questão de análise para nós é quanto às dificuldades, em especial ao fato da reprovação no segundo ano em 2014.

P: $\mathrm{O}$ ano passado, como é que foi o ano passado? $\mathrm{O}$ ano passado ele participou das atividades do CRAS lá de matemática, né? Ele gostava?

M: Da atividade de lá ele gostava.

P: $\mathrm{O}$ que ele falava das atividades?

M: Ele gostava das atividades com o professor Cristiano ele gostava muito, mas na escola ele não gostava.

P: Por que você acha, que ele não gostava da escola?

M: Ele disse, que porque todo mundo falava mal, porque ele tem problema auditivo.

P: Ah, ele tem problema de audição?

M: Ele tem.

P: Foi diagnosticado?

M: Foi.

P: E o que acontecia na escola?

M: Aí não explicava direito pra ele, falava muito baixo, aí ele acabava não ouvindo, aí ficando se perdendo todos os pedaços da tarefa, das explicações, até que ele nem passou de ano, reprovou o ano passado. Mas esse ano tá indo bem graças a Deus.

P: Que série que ele está?

M: Tá no segundo ano.

P: Ele tá com 7 anos?

M: Tá com 8 anos.

P: Com 8 anos no segundo ano.

M: Segundo ano, era pra tá no terceiro ano, mas ele reprovou. Aí agora ele tá com uma nova professora a Yolanda, maravilhosa, tá indo bem graças a Deus, tá desempenhando bem o papel dele e foi bem proveitoso o que ele aprendeu com o professor Cristiano, porque ele agora faz as "tarefinhas" dele de matemática sem precisar ajuda, e foi bem proveitoso esse tempo que ele teve lá fazendo aquele trabalho.

Para Maria, Rochinha gostava da participação das atividades matemáticas no Centro de Atividades e mais, isso contribuiu para suas aprendizagens matemáticas, mas na escola a realidade era diferente, sobretudo em função de um fato revelado pela mãe, que Rochinha tem deficiência auditiva e não possui prótese, o que dificulta a comunicação. No ano de 2014, a professora, segundo Maria, não 
tinha a atenção necessária, mesmo sabendo de sua deficiência auditiva, fazendo com que perdesse partes das explicações, o que implica a perda dos significados dos conteúdos. Neste ano, ele está indo bem, pois, além das aprendizagens realizadas no Centro, a professora é presente e consegue realizar a comunicação com ele.

Vale ressaltar que o pesquisador não estava ciente de tal deficiência auditiva, mas que a configuração da realização das atividades no Centro, sempre em pequenos grupos, com muitas trocas, com atendimento individualizado, com atenção um a um, deve ter permitido a plena comunicação de Rochinha, compreendendo sempre os comandos e se engajando nas atividades. Em momento algum a coordenação do CRAS ou do Centro de Atividades informaram tal deficiência auditiva nem mesmo sua mãe, apesar de nosso contato pessoal constante.

Nesse ponto, retomamos o fato das dificuldades de Rochinha com questões tanto da estrutura do número quanto da construção e registro de operações, em que a dificuldade da espacialidade, conforme apontamos nas análises iniciais, revelam-se como empecilho à aprendizagem matemática. Com a existência de uma deficiência auditiva, podemos perceber que a questão da espacialidade não é um problema de ordem cognitiva ou de déficit cognitivo, mas das próprias formas de relação com o espaço e produção de registros, como já pudemos constatar em análises de produções matemáticas de outras crianças com deficiência auditiva (MUNIZ, 2004). As formas diferentes de espacialização não podem ser assumidas como dificuldades nas produções de registros, mas como possibilidades de produções diferenciadas carregadas de sentidos subjetivos e como fonte de produção de configurações subjetivas no fazer matemática, o que tem sido negligenciado nos processos educativos escolares.

São formas diferenciadas de produções espaciais no trato com os números, que são consideradas pela escola como fator de não aprendizagem matemática e redundando na retenção de Rochinha no segundo ano escolar. Não há evidência de a escola se debruçar sobre as produções matemáticas na busca das efetivas causas de sua dificuldade na construção de procedimentos e registros matemáticos.

Quanto às percepções da mãe em relação às dificuldades de Rochinha, sua fala revela que sua percepção sobre suas aprendizagens matemáticas é parcial e mesmo a paciência que tem de ajudálo não corresponde ao que presenciamos no Centro e na escola, quando muitas vezes Maria ficava irritada e agressiva com o filho por ele não "prestar atenção" às tarefas, mas parece que esta é uma história que ficou no passado:

P: E no passado quando você viu que ele estava com dificuldade na escola, que ele estava desmotivado você tentou ajudar ele? Como é que foi isso? Você tinha paciência, como é que era?

M: É, eu sempre tenho. Quando eu vejo que não tá conseguindo aprender eu sento, vou lá ajudo a fazer as "tarefinhas", explico como é que é, mas quando chegava na escola ele não tinha muita atenção e ele pegava e largava tudo pra lá. 
P: Você acompanhando ele, o que você percebeu, quais eram as dificuldades dele assim em termo de matemática? O que você percebeu que ele não estava conseguindo aprender, fazer? M: Às vezes a divisão, ele não conseguia dividir direito, subtração às vezes ele não conseguia.

P: Que tipo de subtração que ele não conseguia?

M: A subtração quase todas ele não conseguia fazer, aí a que ele mais fazia era a adição a que ele menos tinha dificuldade. Mas depois do cursinho que ele fez lá, até que agora ele tá de boa, faz tudinho nem pede minha ajuda é muito raro ele me pedir ajuda agora pra fazer tarefa. Agora a única coisa que ele ainda tem um pouco de dificuldade é porque tem que continuar falando mais alto né, porque não escuta direito aí a professora tem que falar um pouquinho elevado o volume.

Inicialmente, a fala de Maria centra-se na divisão, mas acaba admitindo que a subtração impunha muita dificuldade também, mas com a participação nas atividades matemáticas no Centro (que ela chama de cursinho) estas foram superadas e que neste ano os resultados até agora mostram que essas dificuldades foram superadas, e Rochinha inclusive ganhou autonomia e motivação para as atividades matemáticas escolares.

A questão da deficiência auditiva revela-se como um fato negligenciado tanto pela escola quanto pela equipe do Centro, tanto que em momento algum relataram esse fato ao pesquisador, mesmo quando Rochinha evadia-se das atividades matemáticas, por perceber que não daria mais conta de produzir respostas:

P: Mas a professora do ano passado também não sabia que ele tinha problema auditivo?

M: Sabia, mas ela não dava muita importância.

P: Não dava. O pessoal do CRAS sabia também?

M: O pessoal também sabia, todo mundo lá da escola sabe que ele tem problema.

$\mathrm{P}: \mathrm{E}$ o que você acha que às vezes ele fugia da oficina de matemática, que ele não queria às vezes ficar? Por que você acha que às vezes ele não queria ficar?

M: É porque ele fala que achava que todo professor era igual, que não ia dar muita atenção pra ele, que nem ia dar explicação pra ele igual pra todo mundo, não ia dar uma atenção especial pra ele, tanto que depois ele passou a ficar direitinho, né? No começo ele fugia das aulas.

Assim, os sentidos subjetivos produzidos por Glauber associados à falta de atenção dos professores, pois considerava que todos os professores iriam negar-lhe a possibilidade de uma comunicação efetiva, o que acabou não acontecendo nas atividades de Matemática no Centro.

Suas fugas podem ser interpretadas como forma de distanciamento do sujeito em relação à situação que vê como contexto de impasse, de impossibilidade de transpor, sem chance de superação, pois não via como encontrar ajuda, visto que a ajuda e a mediação pedagógica sempre lhe foram negadas na escola do ano passado. Se não pode ter ajuda, não se auto expor ao seu bloqueio é uma estratégia de se 
proteger dentro do grupo. Ao se isolar, acaba por instituir um círculo vicioso, uma vez que, socialmente isolado, não há como oferecer-lhe ajuda e, por consequência, a aprendizagem não se realiza, reforçando sua autoimagem de não capacidade de superação de situações matemáticas.

Para ampliar a visão das capacidades e dificuldades de Rochinha, levamos a uma discussão com Maria sobre a vida de Rochinha para além da escola:

P: E em casa? Quais as dificuldades que você percebe que ele tem em casa, quais são as facilidades? Como é o dia-a-dia dele?

M: Ah, ele gosta de ajudar a arrumar a casa.

P: Ah, ele participa.

M: Ele participa, ele adora me ajudar a lavar roupa, ele ama! Ele não gosta muito de varrer, eu falo, meu filho vai varrer ali pra mamãe, vai! Ele não gosta muito. Banheiro: essa história não é mais ele, mas eu vou lavar roupa ele tá ali do meu lado, tanto que só ele me ajuda a lavar roupa, os outros quase que não fazem isso, essa tarefa é dele mesmo. Ele me ajuda a pendurar todas, me ajuda a tirar do varal, às vezes ele vai lá e tira tudo sozinho, ele tem bastante facilidade assim para me ajudar em casa, ele gosta de organizar o quarto dele, gosta do quarto dele arrumado, a caminha dele esticadinha, tudo arrumadinho, os ursos todos em cima da cama, tudo arrumadinho.

P: Ele já fez compra? Ele manipula com dinheiro, ele conhece cédulas?

M: Ele vai no mercado ele conhece, conhece cem reais, cinquenta, vinte e cinco, vinte, dez, cinco, tudo ele conhece.

P: Ele se preocupa com troco?

M: Ele se preocupa, ele sabe direitinho. Eu posso dar cinquenta reais pra ele e falar, filho vai buscar um suco pra mamãe, ele vai e quando ele chega, chega com o troco certinho. Ele sabe fazer conta, ele gosta de matemática.

P: Ele faz uma poupancinha dele? Junta dinheiro com moedinha?

M: Faz, junta o dinheiro dele, toda mesada dele ele guarda.

P: Ele tem mesada?

M: Todo mês eu dou dez pra cada um, né. Ele vai lá e guarda o dinheirinho dele.

P: Ele não é gastador não?

M: Não. Aí ele fala assim mamãe se você estiver precisando eu te empresto, você me paga próximo mês. Ele me empresta o dinheirinho dele e aí depois quando eu recebo eu acerto com ele. Ele não gosta de gastar muito dinheiro à toa. Ele gosta de gastar o dinheiro dele comprando carrinho, ele ama carrinho. Ele até que queria uma coleção da Hot Whells, eu falei, eu não tenho grana pra te dar é muito dinheiro. Mas a madrinha dele deu pra ele de presente de Natal.

(...)

P: Ele reconhece o horário, a hora? Se situa no tempo? 
M: Ele sabe.

P: Sabe.

M: Ele acorda de manhã, por exemplo, e fala: - Mãe já tá na hora de ir pra escola são seis horas, já se arruma, já levanta, já se ajeita, vai pra escola. Ele sabe mais ou menos os horários que começam os desenhos dele à tarde, as novelas que ele gosta á tarde. Ele geralmente sabe essas coisas, sabe tudo.

Além da grande participação na vida cotidiana da família, mostrando-se colaborador e alegre, Rochinha apresenta bom conhecimento dos valores monetários, consegue realizar operações com cédulas e moedas, sem que as operações realizadas tenham de ser expressas na forma de registros gráficos, o que é excessivamente valorizado pela escola, desprezando na avaliação das capacidades matemáticas das crianças suas habilidades com cálculos mentais, aproximações, arredondamentos, estimativas, essa capacidade é revelada na atividade lúdica realizada no Centro de Atividades com os jogos como a vendinha, mas sem atividade de registros matemáticos, uma vez que as operações eram somente mentais assim como apoiadas na manipulação das cédulas, por meio de composições dos valores monetários.

Rochinha, segundo a fala de Maria, tem um poder de agir sobre seu micromundo a partir de conceitos e procedimentos matemáticos não reconhecidos e, portanto, desvalorizados pela escola, uma escola que valoriza tão somente os conhecimentos matemáticos que aparecem como produções escritas, justamente em contextos de produções que Rochinha tem dificuldade em função de seu desenvolvimento de espacialidade, traço de sua deficiência auditiva. $\mathrm{O}$ problema maior parece-nos ser o fato de a escola reprovar a criança no segundo ano de escolaridade, avaliando tão somente suas dificuldades e negando-se a reconhecer todo um potencial para a aprendizagem matemática, o que constitui a base para a aprendizagem da mesma. E Maria conclui "ELE SABE TUDO", mas um tudo não reconhecido pela escola.

Ao final, Maria assim sintetiza a fase atual de Rochinha, superada a crise de uma vivência pouco produtiva na vida escolar do ano anterior:

P: E hoje ele tá gostando da escola?

M: Hoje ele tá graças a Deus!

P: Por que você acha que hoje ele tá gostando da escola? Quais as diferenças que você vê Maria?

M: Porque a professora dá mais atenção.

P: Atenção.

M: Mais carinho, ela é mais cuidadosa, ela se mantém na sala de aula é muito raro ela sair, ela tá sempre ali explicando, quando tem uma dificuldade ela tá ali do lado. A professora dele esse ano é maravilhosa, espero que não troque.

P: E hoje ele tá fazendo dever de casa? 
M: Tá fazendo dever sozinho, ontem mesmo ele fez toda "tarefinha" dele sozinho.

P: E você acompanha?

M: Acompanho, ele termina de fazer eu vou olhar pra ver como é que tá.

$\mathrm{P}: \mathrm{E}$ tem algum momento que ele se mostra preguiçoso?

M: Às vezes ele fala: - Ai minha mão tá doendo! Eu, não filho tem que terminar, depois que terminar você pode brincar. Ele vai lá e termina e aí volta às brincadeiras de sempre.

P: Beleza. O que mais você vai fechar em relação ao seu príncipe?

M: Ah, meu principezinho ele é muito amado, ele é maravilhoso, ele agora tá uma criança assim, meio "impliquentinha” com a irmã dele, mas eu acho que é fase, né? Mas passando daí, é uma criança doce, amável, é bem dedicada.

Participou das atividades no Centro a irmã de Rochinha, Tiana, 11 anos, diferentemente dele, não apresentou dificuldades significativas, sempre muito envolvida, aplicada e plena de energia e alegria, o que de certa forma provoca influências sobre os comportamentos de Rochinha, uma vez que é vista como criança de sucesso e plena de capacidades. Mas deixaremos para tratar primeiro da análise das participações de Tiana e suas produções, para então voltarmos à discussão das possíveis influências dela sobre o irmão. Podemos hipotetizar que sentidos subjetivos produzidos no contexto familiar, articulados com outros no contexto escolar, tenham participação na produção das dificuldades de aprendizagem de Rochinha.

\section{Considerações}

Há um avanço neste estudo ao favorecer a compreensão mais abrangente da constituição do ser matemático como aquele que aprende e produz sentidos subjetivos sobre seus processos de aprendizagem e de constituição enquanto sujeito inteligente para tratar de desafios em contextos de resolução de problemas, em especial, de situações matemáticas.

O olhar para essas crianças, no processo de constituição ao longo de sua vida de construção social desses seres humanos, que participaram das experiências de matemática lúdica, revela o quanto os esquemas mentais, presentes em dada situação matemática, não podem ser compreendidos e explicados, limitando-se à situação em si, como fenômenos cognitivos pontualmente considerados, uma vez que os processos cognitivos e a dimensão simbólico-emocional da experiência encontram seus fundamentos psicológicos na trajetória de vida desses sujeitos matemáticos, com experiências e significados que o próprio sujeito não tem consciência. A busca pela captação das lógicas da constituição subjetiva do ser matemático encontra na Epistemologia Qualitativa (GONZÁLEZ REY, 2002, 2014) ferramentas que nos permitiram a produção de informações acerca da gênese dessa complexa constituição do ser matemático enquanto produtor de sentidos subjetivos de sua capacidade em aprender matemática. A epistemologia qualitativa favoreceu a produção da informação e da produção teórico-metodológica, exigindo do pesquisador um esforço intelectual interpretativo na busca do reconhecimento de uma linha lógica de constituição do sujeito, uma linha nada linear, mas trançada, embaraçada pelas 
experiências e seus significados e sentidos pelo sujeito em sua trajetória social, coletiva e solidária.

O estudo permitiu a construção do conhecimento da constituição subjetiva desses sujeitos, enquanto seres matemáticos, construção que, infelizmente, educadores e escolas desconhecem, colocando em xeque os alicerces da definição do diálogo pedagógico, uma vez que esse diálogo revela-se fragilizado a partir do desconhecimento de quem é esse que aprende, que quer aprender, em especial, aprender matemática, produzindo sentidos subjetivos, cujos alicerces extrapolam sobremaneira as relações, os conhecimentos, as representações, os muros e os tempos da escola.

Isso acaba por revelar o quanto o "diálogo" na escola, enquanto espaço pedagógico ou de investigação científica, sempre se mostra limitado e fragilizado, sobretudo na análise das produções matemáticas de nossas crianças e jovens. Isso traz novas lógicas e bases epistemológicas para os estudos e investigações em Educação Matemática, a partir das contribuições da Teoria da Subjetividade (GONZÁLEZ REY, 2002, 2008, 2012, 2014), fazendo com que passemos a levar em consideração, no complexo processo de aprendizagem matemática, não só os sistemas cognitivos de geração de esquemas mentais, mas também a importância na definição dos processos de aprendizagem os sistemas simbólico-emocionais, os quais determinam a natureza da produção do conhecimento matemático, qualificando-a.

A relação dialógica, constituída por esquema mental-configuração subjetiva, aponta que, se de uma parte há desenvolvimento de conceitos-procedimentos na aprendizagem matemática, como vimos no caso analisado, de outra, a relação dialógica gera sentidos subjetivos sobre sua capacidade de aprender matemática no contexto de superação de desafios e dificuldades. O estudo revela que os processos cognitivos de pensar e fazer matemática, em especial na infância, dependem fortemente dos sentidos subjetivos do sujeito, seja do sistema simbólico-emocional construído em experiências pretéritas, seja nas experiências presentes. A visão de si que o sujeito possui, a autorrepresentação enquanto ser matemático, permeado pelo complexo sistema simbólico-emocional na produção de sentidos objetivos, define para o sujeito o que ele pode ou deve realizar enquanto matemático, dentro da escola e fora dela (como foi o caso deste estudo). Entretanto, foi na articulação da Teoria da Subjetividade, com a valorização do sujeito que aprende como produtor de sentidos subjetivos, atrelada ao método da Epistemologia Qualitativa que pudemos constituir um espaço dialógico com esses pequenos seres matemáticos que nos permitiram trazer para a análise elementos do complexo sistema simbólico-emocional, dando-nos uma nova lente epistemológica na forma de ampliar e aprofundar a compreensão dos processos histórico-social-emocional-cognitivo do permanente processo de constituição do ser matemático: como a criança percebe-se como sujeito inteligente, capaz de dar respostas e validá-las, de extrapolar limites, descobrir alegrias na possibilidade de estar sempre aprendendo matemática.

O estudo demonstra o quanto tais crianças, como é o caso de Rochinha, criança em situação de risco social e deficiente auditivo, revelam querer aprender decorrente de uma crença na capacidade ontologicamente existente, que foi um importante elemento de análise observado em nossos sujeitos, que sempre quiseram dar respostas, mostrando-se capazes, crianças que, mesmo em contexto de "risco 
social”, têm mães que, não obstante o baixo nível de escolaridade, buscam estimular suas crianças para a aprendizagem e desenvolvimento pleno. Esse é um dos motivos pelos quais essas crianças se fazem presentes, no Centro de Atividades, especialmente entusiásticas das oficinas de matemática (que sempre as desafiam), mesmo após a conclusão da pesquisa.

Além desses resultados das relações dialógicas e complexas entre produção de sentidos subjetivos e a geração de esquemas mentais, reconhecemos, na constituição das oficinas de matemática lúdica, no contexto da inclusão social, a oportunidade de as crianças conceberem a possibilidade de "aprender brincando" no contexto de uma aprendizagem bem distinta de suas experiências matemáticas escolares. A descoberta dessa nova dimensão de produção e aprendizagem matemática permite uma mudança no próprio sistema de produção de sentidos subjetivos dos sujeitos. Suas capacidades de aprender matemática e o significado dessas aprendizagens em suas vidas fazem com que o sujeito se confronte com sistemas de sentidos de subjetividade social da matemática, acabando por descobrir que a aprendizagem matemática pode não ser excludente e mais, pode até ser lúdica.

Nesse contexto, a construção de diálogo com as crianças fora das oficinas lúdicas e com suas mães, após as análises microgenéticas de seus registros matemáticos, mostrou-se valorosa no sentido do alargamento epistemológico da constituição complexa e tortuosa desses sujeitos que aprendem, algumas vezes, aprendem apesar da escola.

Um dos desafios que fica em aberto ao final deste estudo e que nos motiva à continuidade no campo da investigação matemática é o de trazer os estudos da Teoria da Subjetividade para a Educação Matemática, na busca da compreensão do ser matemático enquanto produtor de sentidos subjetivos e de criatividade matemática. Algumas novas questões nos são impostas pelo estudo realizado:

\section{Referências}

Muniz, C. A. (2001). Educação e Linguagem Matemática. In S. M. Bortoni-Ricardo (1a Ed.), Organização do Trabalho Pedagógico. Brasília: Universidade de Brasília, 1-2, 07-94.

Muniz, C. A. (2009). A produção de notações matemáticas e seu significado. In M. H. Fávero, \& C. Cunha. (1 ${ }^{\mathrm{a}}$ Ed.), Psicologia do Conhecimento: o diálogo entre as ciências e a cidadania. Brasília: Unesco e UnB, 1, pp 115-143.

Muniz, C. A., \& Bittar, M. (2009). O conceito de "esquema" para um novo olhar para a produção matemática na escola: as contribuições da Teoria dos Campos Conceituais. In C. A. Muniz, \& M. Bitttar (org.), A aprendizagem matemática na perspectiva da Teoria dos Campos Conceituais. 1ed. Curitiba: Editora CRV, 1, 1-93. 
Muniz, C. A. (2004). Mediação do conhecimento matemático: re-educação matemática. Revista Ícone, 10, 1, 59-72. ISSN 0104-8104.

Rey, F. G. (2002). Pesquisa Qualitativa em Psicologias: caminhos e desafios. Tradução: Marciel Aristides Ferrara Silva. São Paulo: Pioneira Thomson Learning.

Rey, F. G. (2008). O sujeito que aprende: desafios do desenvolvimento do tema da aprendizagem na psicologia e na prática pedagógica. In M. C. V. R. Tacca (2a Ed.), Aprendizagem e Trabalho Pedagógico. Campinas: Editora Alinea.

Rey, F. G. (2012). A configuração subjetiva dos processos psíquicos: avançando na compreensão da aprendizagem como produção subjetiva. In M. A. Mitjáns, B. J. L. Scoz, \& M. I. S. Castanho, Ensino e Aprendizagem: a subjetividade em foco. Brasília: Liber livros.

Rey, F. G. (2014). Ideias e modelos teóricos na pesquisa construtivo-interpretativa. In A. M. Mitjáns, \& M. M. V. Neubern (org.), Subjetividade Contemporânea: discussões epistemológicas e metodológicas. Campinas: Alinea. ISBN 978-857516-703-8

Vergnaud, G. (1994). L’enfant, la mathématique et la réalité. Paris: Peter Lang.

Vergnaud, G. (1998). Qu'est-ce que la pensée? dans les actes du Colloque: Qu'est-ce que la pensée? Suresne, Laboratoire De Psychologie Cognitive et Activités Finalisées, Université Paris VIII, 1-21.

Vergnaud, G. (2009). O que é aprender? In C. A. Muniz, \& M. Bitttar (1ª Ed.), A aprendizagem matemática na perspectiva da Teoria dos Campos Conceituais. Curitiba: Editora CRV,1,1-93. 